\title{
FLORACIÓN Y TURISMO EN MALLORCA Y EL BAIX SEGRE: DOS CASOS EMBLEMÁTICOS DE IMAGEN DE MARCA TURISTICO-PAISAJÍSTICA
}

\author{
Gabriel Alomar Garau \\ Departament de Geografia, Universitat de les Illes Balears, \\ Edifici Beatriu de Pinós, Carretera de Valldemossa, km 7.5, \\ 07122 Palma, Mallorca, España \\ gabriel.alomar@uib.es \\ Marc Hidalgo Jiménez \\ Ajuntament de Soses, \\ Plaça de I Ajuntament, 1, 25181 Soses, Lleida, España \\ geomarchidalgo@gmail.com
}

\begin{abstract}
Resumen: En el presente trabajo se describen dos casos consolidados de turismo de motivación paisajística: la floración invernal de almendros en Mallorca (Islas Baleares) y la floración primaveral de frutales de clima templado en la subcomarca del Baix Segre (Cataluña). El objetivo es presentar una reconstrucción sintética del proceso histórico de formación de estos cultivos arbóreos, y su constitución como imagen de marca paisajística en ambas regiones, así como su incorporación al mercado turístico bajo la conocida fórmula del turismo ambiental y cultural. En Mallorca, las prácticas de ocio y turismo en torno a la floración operan como alternativa al modelo de 'sol y playa', mientras que en el Baix Segre constituyen su más importante contribución a la modalidad de turismo rural. El alcance del par floración y turismo ha sido todavía poco estudiado, de ahí que merezca un estudio que pretende servir de base para futuros trabajos sobre el tema.
\end{abstract}

Palabras clave: Turismo florístico, paisaje, turismo rural, imagen de marca paisajística. 


\title{
Flowering and tourism in Mallorca and Baix Segre: Two emblematic cases of a tourist-landscape brand image
}

\begin{abstract}
In this paper, two consolidated cases of landscape-motivated tourism are described: the winter flowering of almond trees in Mallorca (Balearic Islands) and the spring flowering of temperate fruit trees in the Baix Segre sub-region (Catalonia). The objective is to present a synthetic reconstruction of the historical process of formation of these tree crops, and their constitution as a landscape brand image in both regions, as well as their incorporation into the tourist market under the well-known formula of environmental and cultural tourism. In Mallorca, leisure and tourism practices around flowering operate as an alternative to the 'sun and beach' model, while in Baix Segre they constitute their most important contribution to the rural tourism modality. The scope of the flowering and tourism pair has still been little studied, hence it deserves a study that aims to serve as a basis for future works on the subject.
\end{abstract}

Keywords: Flowers tourism, superblooms tourism, landscape, rural tourism, landscape brand image.

\section{Introducción}

El viaje turístico es hoy, en la era de la imagen, una experiencia paisajística. Sustentado en la actividad agraria y/o jardinera desarrollada en el lugar de destino, el turismo florístico ha conseguido posicionarse como una alternativa más de ocio, desarrollado principalmente en el ámbito rural y ligado a la apreciación y la experiencia estética del paisaje, y por tanto al consumo de emociones y sensaciones. En Europa, si bien en sus inicios el turismo en este ámbito se planteó como una manera de aumentar la renta de las familias dedicadas a la agricultura, hoy en día no siempre es válida la fórmula que liga la práctica agraria a la etiqueta de turismo rural (Busby y Rendle, 2000). Con el tiempo, éste ha llegado a constituir una actividad con autonomía propia, que además compite con el agricultor por la tierra y por el trabajo (Hermans, 1981).

Tanto en Mallorca como en el Baix Segre, el turismo de floración constituye una opción consolidada dentro del variado conjunto de actividades turísticas que la clasificación clásica y pionera de Smith (1989, p. 4-6) divide en turismo étnico, turismo cultural, turismo histórico, turismo recreacional y turismo ambiental (o su equivalente reciente bautizado con el nombre de 'ecoturismo'). Éste último se combina por lo común con el turismo étnico y cultural, y es el que atrae a un tipo de turista interesado en la visita a ciertos territorios en los que se conservan un conjunto de prácticas que expresan relaciones históricas y culturales entre el hombre y su medio, tal como ocurre con la agricultura tradicional. 
El estudio del turismo asociado al fenómeno de la floración estacional no es nuevo (Turpie y Joubert, 2004; Xie, Wang, Meng y Xiao, 2005; Ryan, 2011; Tao, 2011; Padilla y Such, 2001; Cohen y Fennell, 2019, entre otros), pero sí lo es en el caso del presente trabajo, cuyo objetivo es describir el desarrollo, en la subcomarca natural catalana del Baix Segre (comarca del Segrià) y en el interior de la isla de Mallorca (Islas Baleares), de un tipo de visita turística motivacionalmente centrada en la apreciación estética de los árboles en flor.

Hay que decir que el turismo de floración arbórea, ligado parentalmente al llamado turismo botánico (Pickering y Ballantyne, 2013) o el destinado a la visita de jardines históricos (Ballantyne, Packer y Hughes, 2008), puede inscribirse aparentemente en la mencionada modalidad de ecoturismo (o turismo ecológico), en el sentido de que se trata de una actividad que depende de un recurso natural poco o nada transformado y cuya finalidad es estudiarlo o admirarlo. Sin embargo, en el caso que ahora examinamos no cabe atribuir a los árboles en flor un estado silvestre, pues se trata de árboles cultivados y controlados morfométricamente, es decir especies vegetales plenamente domesticadas. En cualquier caso, el turismo florístico es un turismo de tipo eminentemente rural, pues el espacio en el que se desarrolla tiene por lo común las típicas características de un ambiente rural.

Desde un punto de vista paisajístico, en el invierno tardío de Mallorca y en la primavera del Baix Segre, la masiva floración de los árboles tiene el resultado de un espectáculo, de ahí que en estas dos regiones la floración opere no sólo como decorado de las actividades turísticas que puedan llevarse a cabo, sino como el elemento que justifica por sí mismo la frecuentación turística del lugar. Siguiendo la clasificación de Lozato-Giotart (1990) relativa a los tipos de sitios en función de su papel turístico, los lugares en los que tiene lugar la floración estacional son sitios-decorados naturales y en parte urbanizados -los pueblos rurales-, que tienen una base histórica y cultural. También constituyen sitios-envoltorio, pues en ellos se explota el tipismo. Además de esto, el espacio geográfico en el que se desarrolla el turismo de flora responde bien a la noción de 'región turística' (Lozato-Giotart, 1990) en la medida en que se constituye como un área de frecuentación turística y con una imagen de marca que la caracteriza.

Por otro lado, hace ya años que el cuadro motivacional del turista se ha ampliado sustancialmente, y en relación con el ocio turístico asistimos a la aparición de nuevos paradigmas que se inscriben en una nueva sociedad que ya no se comporta ni como fordista ni como moderna, sino como posfordista y postmoderna. El turismo de las cuatro S en inglés (sun, sea, sand, sex) -el que Smith (1989) cataloga como turismo recreacional-, convive hoy con el turismo de las cuatro E en francés (environnement, événement, équipement, encadrement: medio ambiente, acontecimiento, equipamiento-infraestructura y decorado-paisaje). Esto significa que al consabido viaje vacacional de descanso y ocio se ha venido sumando un tipo de viaje experiencial que cubre un amplio espectro de posibilidades (Cohen, 2004), desde el llamado turismo 'de aventura' 
al mencionado turismo étnico. Si el turismo puede ser definido como aquel "desplazamiento en el espacio realizado por personas con el fin de servirse de otros espacios como lugares de ocio, bien para disfrutar de los recursos y atractivos geofísicos diferenciales que ofrece el territorio al cual se acude, bien para contemplar elementos genealógicos contenidos en él" (Sánchez, 1985, p. 104), puede decirse que toda actividad turística es demandadora y consumidora de espacio geográfico. Éste, a su vez, está conformado por un 'continente' (el medio natural: clima, geología, flora, fauna, aguas) y un 'contenido' (los artefactos humanos creados en el medio) (López Palomeque, 1994). En clave turística, el espacio geográfico así definido y los elementos que lo constituyen se erigen como soporte y como recurso de la actividad turística. Ahora bien, para que ésta pueda desarrollarse se necesita de una estrategia que pasa necesariamente por la creación de una imagen de marca del espacio geográfico considerado.

El estudio de la imagen de marca territorial como forma de publicidad turística ha despertado el interés investigador desde hace tiempo (Miossec, 1977, entre otros), y en España cuenta ya con algunos precedentes (San Eugenio y Barniol, 2012; Cebrián, 2013). Sin embargo, son escasos los que han abordado el caso de la imagen de marca de la isla de Mallorca (Alzaga, 2005), mientras que en el caso de la subcomarca catalana del Baix Segre es un tema todavía por explorar. En todos ellos, la construcción de una marca turística basada en los elementos caracterizadores del territorio busca generar una propuesta que sea diferenciadora y capaz de generar entusiasmo en el público al que se dirige. Para esto es habitual recurrir a los valores estéticos del territorio, de ahí que el paisaje, entendido como experiencia sensorial y emocional de un fragmento de ese territorio, sirva eficazmente para estos fines. En los casos que examinamos de Mallorca y el Baix Segre, el capital activo del que se nutre su imagen de marca paisajística es su riqueza en árboles frutales y la floración estacional de los mismos, y la experiencia turística que proveen los espacios rurales en los que ocurre el fenómeno son experiencias que Sharpley y Jepson (2011) califican de "espirituales". Como se verá, la creación del imaginario paisajístico de Mallorca, en el que la floración de los almendros ocupa un lugar preeminente, arranca con la literatura europea de viajes, de espíritu romántico. En el caso de la comarca del Segre, es un imaginario más reciente y está en vías de formación.

Por último, hay que decir que en el presente trabajo entendemos el paisaje no como un objeto espacial con unas cualidades físicas distintivas, sino como experiencia o vivencia emocional de ese espacio. No hay paisaje sin un sujeto que lo construye -aunque también es una construcción social-, de ahí que la noción de paisaje quepa aplicarla no tanto a la apariencia del espacio geográfico sino más bien a una manera de mirarlo. Para Tuan (1979, p. 90), el paisaje "aparece ante nosotros a través de un esfuerzo que la imaginación ejerce sobre una serie de datos sensoriales muy seleccionados. Es un logro de la mente madura". Para Cosgrove (1998, p.13) "no es sólo el mundo que vemos, sino que es una construcción, una composición de este mundo. El paisaje es una manera de ver el mundo". Este es el sentido en el que entendemos que los campos de frutales en flor se revelan en la mente de sus espectadores como una imagen 
que el turista valora en términos de placer estético. Por eso va a su encuentro buscando la experiencia del placer de los sentidos. Preferentemente el sentido de la vista, pero también el del olfato y del gusto.

\section{Metodología}

Fruto de la falta de datos estadísticos oficiales y específicos relativos al turismo de floración estacional en las regiones estudiadas (número de visitantes relacionados con el sector, inversiones realizadas, percepción social de los paisajes de frutales), el presente trabajo adopta un carácter descriptivo, por el cual se relatan dos casos vivos y emergentes de turismo de floración en España. El método adoptado es, por tanto, cualitativo, y ha permitido evaluar ciertas características territoriales de Mallorca y el Baix Segre, que han sido aprovechadas para generar una marca turística de corte paisajístico, centrada en la floración de determinados árboles frutales. Esta evaluación se ha realizado en base a la exploración de ciertas variables de interés, como son el proceso histórico de formación de los cultivos de frutales en las dos regiones, su extensión territorial y sus características como recurso turístico pasado y presente. La reconstrucción resumida de la historia de estos cultivos ha requerido, en cada caso, una amplia consulta bibliográfica a las fuentes (en el caso de Mallorca, fuentes documentales literarias y artísticas, además de las científicas). Si bien nuestro examen no ha podido contar con datos diferenciados de turismo florístico - en cuyo caso el trabajo pudiera adoptar un carácter analítico que estableciera comparaciones de interés-, sí incorpora datos territoriales actualizados de cultivos, que dan cuenta de la huella geográfica de los frutales en las dos regiones, de la que cabe deducir su estampa paisajística. Una parte de estos datos han sido convenientemente tabulados y cartografiados, y provienen del mapa de ocupación del suelo en España correspondiente al proyecto europeo Corine Land Cover (CLC), en la versión más reciente, del año 2018. Otra parte proviene de las bases estadísticas agrarias elaboradas por los departamentos correspondientes del Govern de les Illes Balears y la Generalitat de Catalunya.

\section{Almendros en flor: imagen de marca paisajística y turística de Mallorca}

El primer creador de la 'imagen del lugar' (imago loci) de Mallorca fue seguramente el comisionado napoleónico André Grasset de Saint-Saveur, que a principios del siglo XIX se estableció durante unos años en las Baleares y, fruto de esta estancia, publicó en el año 1807 una obra que lleva por título Voyage dans les iles Baléares et Pibiuses. Es en esta obra pionera donde se encuentran las primeras descripciones literarias y ar- 
tísticas del archipiélago balear, según las cuales sus islas son vistas como un lugar a medio camino entre el exotismo y un mundo arcaico que en la Europa septentrional estaba en vías de desaparición. A partir de la estancia de Grasset en Mallorca, la isla se convirtió durante todo el siglo XIX en destino de artistas, nobles y ricos. El viaje se optimizó a partir de la inauguración, en 1837, de la primera línea marítima regular que enlazaba Palma con Barcelona por medio de un barco de vapor de nombre 'El Mallorquín'. Esos primeros 'turistas' participaban de la experiencia del llamado Grand Tour, y muchos escribieron y publicaron su propio relato del viaje mallorquín: entre muchos otros, J. Carr (Descriptive travels in the southern and eastern parts of Spain and the Balearic Isles, 1811), W. Dodd (Three weeks in Majorca, 1863), Gaston Vuillier (Les îles oubliées. Les Baléares, la Corse et la Sardaigne, 1893), J.W. Clayton (The sunny south. An autumn in Spain and Majorca, 1869) o Ch. Toll Bidwell (The Balearic Islands, 1876), este último miembro de la Royal Geographical Society de Londres.

Esas primeras visitas hay que situarlas en el contexto romántico de la época, según el cual el Mediterráneo sublimado (Seguí, 1995; Bes Hoghton, 2012) devino el objeto de visita predilecto de los viajeros ilustrados del norte de Europa desde finales del siglo XVIII. Estos viajeros practican un tipo de viajes pedagógico-culturales, en parte concebidos como una forma socialmente estipulada para la educación de los jóvenes de la nobleza, en particular la inglesa. La misma palabra tourisme procede de ese tour, viaje o recorrido por el mundo. El diccionario de la lengua francesa de Emile Littré, publicado entre 1863 y 1873, incluyó por vez primera el vocablo touriste para referirse a "aquel que viaja por curiosidad o por distracción". En 1840 el artista francés Jean-Joseph Bonaventure Laurens publica Souvenirs d'un voyage d'art à l'île de Majorque (Recuerdos de un viaje artístico a la isla de Mallorca), ilustrado con cincuenta y cinco magníficas litografías, libro con el que parece que se establece la codificación romántica de Mallorca (Alzaga, 2005). A partir de aquí Mallorca se puso relativamente de moda, y comenzó a aparecer un elenco de obras que dan cuenta de la vivencia paisajística, artística y costumbrista mallorquina. Otras no son propiamente literarias, como la que escribe el archiduque Luís Salvador de Austria, llegado por primera vez a la isla en el año 1867, y que titula Die Balearen in Wort und Bild geschildert (Las Baleares descrita por la palabra y la imagen), publicada entre los años 1869 y 1884. Este magno trabajo tiene el carácter científico de la descripción geográfica y antropológica, aunque su autor utiliza ya la palabra alemana landschaft para referirse, en sentido admirativo, al paisaje.

Serán todos esos viajeros los impulsores de las que más tarde se consolidarían como imágenes de marca paisajística que hoy perviven y se repiten en los eslóganes turísticos al uso. El poeta Rubén Darío se referirá a Mallorca como "la isla de oro por gracia del sol divino", en un libro de 1907 titulado precisamente La isla de Oro. El oro de Mallorca. En 1909, Miquel dels Sants Oliver, director del diario La Vanguardia, publica una obra costumbrista que lleva por título Illa daurada. La ciutat de Mallorques (Isla dorada. La ciudad de Mallorques), apelativo al que también recurrirán escritores y pensadores posteriores, amplificando su difusión, como hace Miguel de Unamuno con En 
la isla dorada, de 1922. Por su parte, el pintor Santiago Rusiñol publicará en 1913 un libro sobre Mallorca que titula L'illa de la calma (La isla de la calma).

A tenor de estos calificativos, Mallorca era retratada como un lugar al que todavía no había llegado la plena industrialización, y que por eso mismo acaso conservaba el ideal bucólico y arcádico de una sociedad agraria pre-moderna. Tampoco el turismo se había industrializado, lo que hace que a finales del siglo XIX, en concreto en 1890, el citado Miquel dels Sants Oliver escriba algunos artículos de prensa propagandísticos en los que plantea las buenas condiciones que reunía Mallorca como posible destino turístico, comparándolas con las que ya tenían países como Suiza, Italia o Francia. Esta propaganda acaba cristalizando en el año 1903, cuando se publica un escrito del secretario de la Cámara de Comercio de Barcelona, Bartomeu Amengual, titulado La industria de los forasteros (es decir, de los extranjeros), para referirse precisamente a la industria turística. Prueba del éxito de esta iniciativa es la construcción de los primeros establecimientos hoteleros: el Grand Hotel abre sus puertas en 1902, siendo éste, hasta la construcción del Ritz en Madrid, el más lujoso de España. En 1929 lo hace el Hotel Formentor. Hacia 1930, el ingeniero Antonio Parietti Coll prestará una especial atención a la planificación de un conjunto de infraestructuras pensadas para la visita turística de motivación paisajística, como la carretera del puerto de Pollença a Formentor o la del difícil desvío hasta el agreste y poco accesible paraje litoral de Sa Calobra, proyecto que fue presentado en la Exposición Internacional de Barcelona de 1929. La incipiente actividad turística encontró el apoyo logístico de las primeras líneas aéreas como Iberia, fundada en 1928. Las primeras urbanizaciones turísticas de Mallorca son de los años 30 (Cala d'Or en 1933 y Palmanova en 1935).

Con posterioridad al año 1945 (esto es, el final de la Segunda Guerra Mundial), los empresarios locales que ya conocían el negocio hotelero y que habían sobrevivido a la guerra iniciaron en 1951 una estrategia de promoción del turismo, consistente en promocionar la isla a través de una campaña conocida con el nombre de Luna de miel en Mallorca, destinada al turismo de origen español (Vives, 2005). Para la campaña se editó un cartel publicitario en el que una pareja de pájaros recién casados se dirigía al nido situado en un almendro en flor. Los pétalos blancos y rosados del almendro evocaban la idílica rusticidad del espacio rural mallorquín, que eventualmente será recorrido por los recién casados peninsulares durante sus excursiones turísticas. Desde entonces, el almendro en flor se convertirá en icono de otras tantas campañas turísticas de promoción, incluida la del primer hotel de lujo de Palma (Figura 1).

Es partir de 1950 cuando se ponen las bases del que será el actual turismo de masas, que a corto y medio plazo operará en Mallorca como principal factor de cambio socioeconómico y paisajístico del siglo XX. Pasada la Segunda Guerra Mundial, en los países industrializados de Europa las sustanciales mejoras de las condiciones sociolaborales de la clase trabajadora permiten su acceso a la periodización de un tipo de vacaciones remuneradas por la propia empresa. Así, si en 1950 llegan 98.000 turistas la 

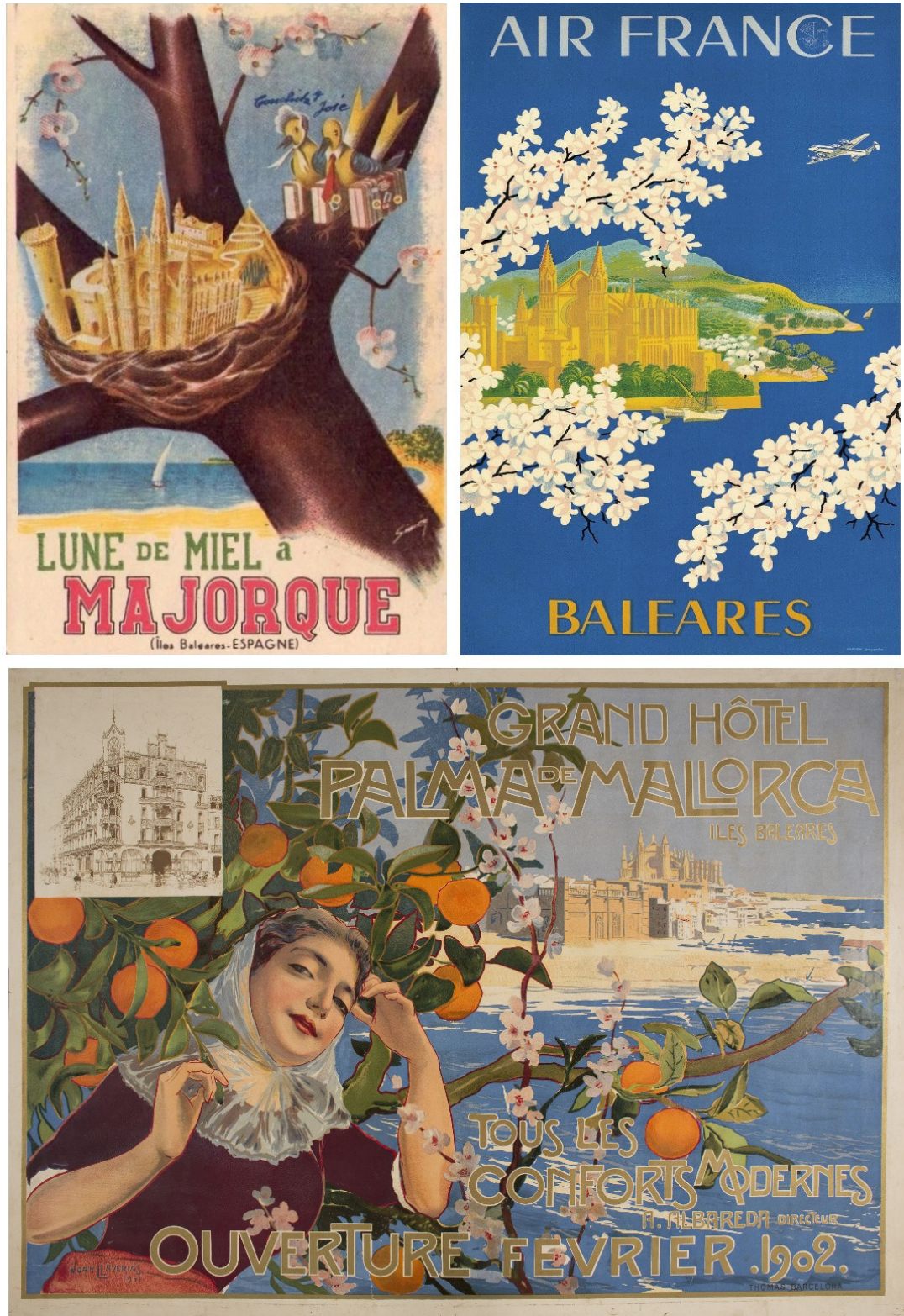

Figura 1. Carteles promocionales del primer turismo en Mallorca. El almendro en flor sirve de icónico reclamo. Arriba a la izquierda, edición en francés de Luna de miel en Mallorca (Fomento del Turismo de Mallorca, 1950). Arriba a la derecha, cartel de la compañía aérea Air France, ilustrado por Lucien Boucher, circa 1951. Abajo, cartel publicitario del Gran Hotel de Palma, de 1901, ilustrado por Joan Llaverias (Museu Nacional d'Art de Catalunya). 
mayoría de los cuales de origen español, en 1959 serán 321.000, mayoritariamente extranjeros. En esta transformación jugará un papel fundamental la aparición del tour operator. Las cifras dan cuenta del éxito del nuevo modelo, pues en 1973 se alcanzan los 2.849.632 de turistas. En 2019, último año disponible del recuento, se habían alcanzado los 11.874.835 (Agencia de Estrategia Turística de las Islas Baleares, 2020).

A partir de 1960, el desarrollo de la actividad turística en las Baleares se ha estudiado a partir del establecimiento de cuatro etapas (Salvà, 1985), cuyas diferencias se basan en el examen cuantitativo del número de turistas. La etapa entre 1994 y 1999 es especialmente remarcable, pues no sólo es la del tercer aumento significativo del número de turistas, sino también porque es cuando el espacio rural de Mallorca se incorpora de lleno a la actividad turística, hasta entonces desarrollada básicamente en la costa. En estos años entran en escena el turismo rural, el residencial y los agroturismos (Barke, 2004), de tal manera que hay una expansión inmobiliaria y turística hacia las áreas rurales que tradicionalmente habían estado reservadas a la vivienda de la población local y a la segunda residencia.

Para entonces, la afianzada imagen de marca paisajística en que se sustentaría el turismo rural, se justificaba y se justifica todavía por los datos de la extensión territorial de los almendros. Así, de acuerdo con las cifras estadísticas básicas agrarias del Govern de les Illes Balears (GOIB, 2018), en el año 2018 la superficie de cultivo dedicada a almendros en producción -es decir, sin contar la superficie abandonada, de autoconsumo o sin producción- era en Mallorca de $18.704 \mathrm{Ha}$, que representan el 10,7\% de la Superficie Agraria Útil (SAU) de la isla $(175.080 \mathrm{Ha})$. Si se atiende a la superficie que ocupa el conjunto de los frutales no cítricos, el almendro representa el 63,2\% (29.594 Ha), cifra que da una idea clara de la impronta territorial y paisajística de este árbol en la isla. A efectos comparativos, el algarrobo ocupa 10.206 Ha y la higuera $366 \mathrm{Ha}$, aunque en este último caso las cifras enmascaran el hecho de que gran parte de su superficie real se encuentra abandonada o sin producción. La superficie del olivar es de 5.304 Ha, y en cuanto a los cítricos (naranjos, mandarinos, limoneros), su superficie productiva es de $1.669 \mathrm{Ha}$. Si se atiende a los datos cartográficos del Sistema de Ocupación del Suelo de España (SIOSE), para el año 2014 la superficie cultivada ocupada conjuntamente por las categorías de frutales no cítricos, otros cultivos leñosos y combinación de cultivos leñosos, era en Mallorca de 45.099,3 Ha. Si bien el SIOSE no permite conocer de manera directa la superficie específicamente dedicada a los almendros, los municipios con mayor extensión de árboles frutales, sin hacer esa distinción, son, en orden descendente, Llucmajor, Manacor, Felanitx, Santanyí, Sant Llorenç, Palma, Inca, Campos, Santa Margalida, Porreres y Marratxí. La misma operación cartográfica se ha realizado con la capa cartográfica de ocupación del suelo del proyecto Corine Land Cover para el año 2018 (Figura 2), cuya categoría 'Frutales' arroja un total de 47.462,9 Ha, siendo los municipios mejor representados Llucmajor $(5651,8 \mathrm{Ha})$ ), Manacor $(5.406,4 \mathrm{Ha})$, Sant Llorenç (3.148,2 Ha), Felanitx (3.099,7 Ha), Santanyí (2.656,8 Ha), Santa Margalida (2.032,1 Ha), Palma (1.798,8 Ha), Marratxí (1.749,3 Ha) y Porreres $(1.683,0 \mathrm{Ha})$, es decir la mayoría de los mismos que señala el SIOSE. 


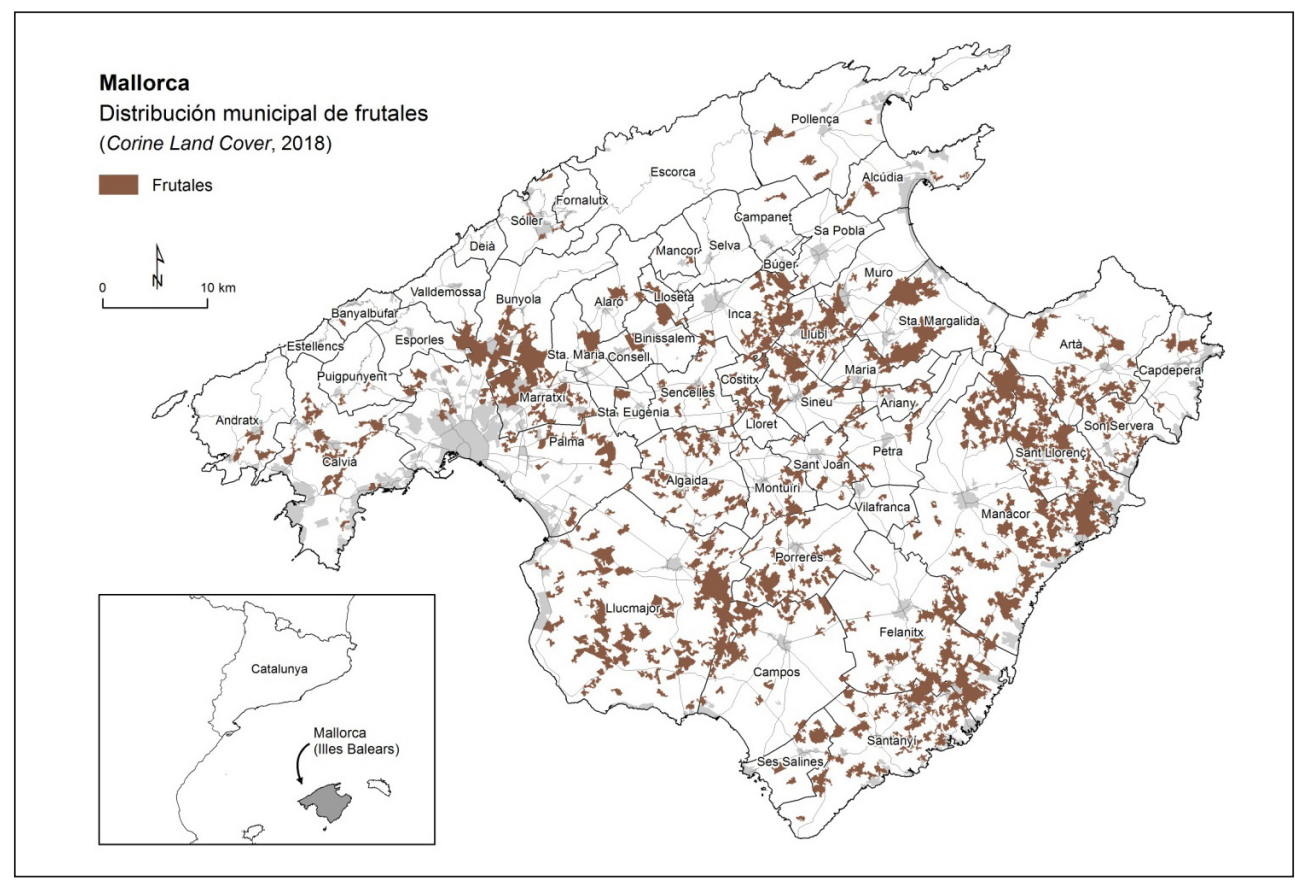

Figura 2. Mallorca (Islas Baleares): Distribución municipal de los frutales (año 2018).

Fuente: Elaboración propia a partir de los datos de ocupación del suelo del proyecto Corine Land Cover, 2018.

Por otra parte, si la Superficie Agraria Útil representaba en 2018 el 48\% del territorio mallorquín (el 41\% es superficie forestal y el 10\% restante no es agrario ni forestal), se trata de un espacio agrario que se caracteriza por su estructura en mosaico, donde los cultivos de frutales se alternan con los herbáceos y los pastos. A esto se unen las zonas improductivas ocupadas por extensas masas de bosques. En numerosos casos ese espacio aparece construido sobre estructuras de piedra seca en forma de bancales, y aparece muy fragmentado formando cercados de piedra (Alomar-Garau, GrimaltGelabert y Bauzà-Llinàs, 2020). Los almendros aparecen principalmente en la unidad de paisaje constituida por el arbolado de secano, tanto en las zonas llanas como en las montañosas. Por lo común, conviven con los pastos en secano asociados con la ganadería, por lo que forman sistemas adehesados.

La introducción masiva de este árbol en los campos de cultivo de Mallorca se debe a las recomendaciones de la ochocentista e ilustrada Sociedad Económica de Amigos del País, que vio en esta planta el sustituto perfecto de las viñas arruinadas por la filoxera hacia finales del XIX. Sin embargo, antes de su introducción masiva, el almendro era ya un árbol conocido. Su origen botánico se halla en zonas continentales del Próximo Oriente 
y Asia Central (Irán, Cáucaso, Turquía y la ribera del Mediterráneo). Los primeros ensayos a propósito del rendimiento del almendro y sus posibilidades económicas se llevaron a cabo en la finca agraria de Son Macià, propiedad del ilustrado Bernardo Contestí, miembro de la filial mallorquina de la Sociedad Económica de Amigos del País. Al ser una planta apta para situaciones de suelo y clima marginales, el éxito de ese y otros ensayos tuvo como colofón su plantación masiva en buena parte del territorio insular.

Si en el año 1860 el árbol ocupaba una extensión de 5.961 Ha en regadío y en secano (Urech, 1869), en 1920 alcanzará las 26.750 Ha y en 1930 las 47.560 Ha. En 1962, año del primer Censo Agrario de España, los almendros de Mallorca se extendían por una superficie cultivada de $41.366 \mathrm{Ha}$ (más del doble que las $18.704 \mathrm{Ha}$ actuales). Para ese mismo año se contabilizaron 4.977.330 de individuos, de los cuales 2.989.000 eran anteriores a 1932, y 4.652.000 eran anteriores a 1952 (Cela Conde, 1979, p.46). Ya que la mayor parte se plantó antes de esa fecha, la avanzada edad de los árboles actuales -o mejor dicho, su mortandad, ya que el almendro vive de promedio unos ochenta años- ha propiciado la plantación de otros nuevos y más jóvenes. Esto, sin tener en cuenta las amenazas de la bacteria fitopatógena Xylella fastidiosa o las del hongo fusicoccum, a las que se une la amenaza del simple abandono por rendición o defunción del campesino que en su día los plantó y los cuidó, además de las periódicas sequías. Hacia 1960, las áreas preferentes de implantación del almendro de secano en cultivo único eran, sobre todo, las de municipios como Palma, Marratxí, Calvià, Llucmajor, Binissalem, Llubí, Sineu, Porreres, Felanitx, Santanyí, Sant Llorenç, Alcúdia o Artà, y en menor medida Puigpunyent, Esporles, Santa Eugènia, Sencelles, Alaró, Pollença, Lloret, Sant Joan, Son Servera y Ses Salines.

Considerando todas las cifras expuestas, el fenómeno de la floración arbórea en Mallorca es especialmente imputado a la floración del almendro (Prunus amygdalus Batsch). Ésta se produce en enero y en febrero, es decir muy tempranamente, ya que el almendro es uno de los árboles que florecen con mayor antelación, cuando por lo común la mayoría de plantas lo hacen en primavera. La huella cultural de este árbol en la isla es tan amplia, que sus variedades han dado lugar a una muy rica lista onomástica (Picornell, 2018). La gran mayoría se ha perdido, y sólo subsisten las de floración tardía para evitar la exposición del árbol ya florecido a las eventuales heladas de irradiación de finales de invierno (también llamadas 'de primavera'). De acuerdo con Saura y Cañellas (1981), las flores del almendro no resisten temperaturas inferiores a $-2,8 \stackrel{\circ}{\circ}$, y el fruto es perjudicado cuando se alcanzan $-1,1 \stackrel{\circ}{ } \mathrm{C}$, de manera que es un árbol especialmente sensible a las heladas en la época de floración y fructificación. Es por esto por lo que para que fructifique óptimamente es necesario un estado benigno del clima, preferentemente soleado y con cielos despejados. Estos requerimientos hacen que resulte problemática su plantación en fondos de valles poco ventilados y con ocasionales nieblas y heladas. 
Las primeras referencias a las bondades paisajísticas de los campos en flor de la Mallorca invernal se encuentran tanto en los mencionados relatos literarios de viajes decimonónicos como en las pinturas de paisaje. En estas piezas abundan y son una constante las referencias a los almendros en flor. Así, el ya citado Archiduque Luis Salvador escribe sobre los omnipresentes almendrales: "En primavera, las dilatadas plantaciones de almendros presentan un aspecto encantador; toda la llanura parece inundada de flores de un blanco deslumbrante que vira a rosado o a marfileño; nada puede competir con la magnificencia de esta vista" (Archiduque Luis Salvador, 1871, p.118). El 2 de abril de 1893, el pintor Rusiñol escribe en el periódico La Vanguardia: "Siguiendo ésta, fuimos andando entre un alegre y bellísimo paisaje. Sin duda para obsequiar nuestra visita se había dispuesto que brotaran á la vez los almendros que se hallaban a lo largo del camino (...). Por ambos lados de la vía, no se veía más que ancha sábana blanca (...); parecía que nadábamos velozmente sobre un lecho de flores". En 1907, en su libro de viajes With a Camera in Majorca, la inglesa Margaret D'Este hace la siguiente referencia de signo poético: "A finales de enero, la llanura alrededor de Palma está adornada con kilómetros de huertos de almendros en plena floración, su leve aroma llena el aire y sus ramas cargadas cubren el país con masas blancas ondulantes (...). En verdad, es un mundo muy hermoso el que contempla esta luminosa mañana de marzo" (d'Este, 1907, pp.34 y 37). Años más tarde, en Palma de Majorque et les Iles Baleares, el francés Pierre Lavedan testificaba retrospectivamente todo ese conjunto literario secular de reseñas en torno a los almendros en flor: "Aún más característico es el almendro, cantado por poetas; Febrero le pone una corona de flores blancas y la coronación del rey de la llanura" (Lavedan, 1936, p. 15).

En el origen y desarrollo de la imagen de marca paisajística de Mallorca también será importante la pintura de tema paisajístico, que antes del XIX no había tenido demasiada repercusión en Mallorca. Sin embargo, a partir de la segunda mitad de ese siglo y sobre todo en el primer tercio del XX entran de lleno en escena los primeros pintores genuinamente de paisaje, en cuyas pinturas impresionistas son recurrentes los campos de almendros: O’Neille (quien en 1862 publica un Tratado de paisaje), Anckermann, Ribas, Mir, Degouve o Rusiñol (Figura 3). Estas y otras muchas referencias al paisaje rural mallorquín colaborarán activamente en el triunfo de la imagen marca de los almendros en flor y su utilización eficaz en las ya mencionadas campañas de promoción turística de la isla. En ellas se consuma la imagen mitificadora de un territorio tildado de "idílico" o "paradisíaco". Aunque estos epítetos magnifican en positivo la realidad paisajística de la isla, ciertamente el mosaico de paisajes y sus cambios tonales y de perspectiva, hacen creíbles adjetivos como esos en no pocos lugares del interior rural insular, principalmente los de la montaña y los del llano central. 


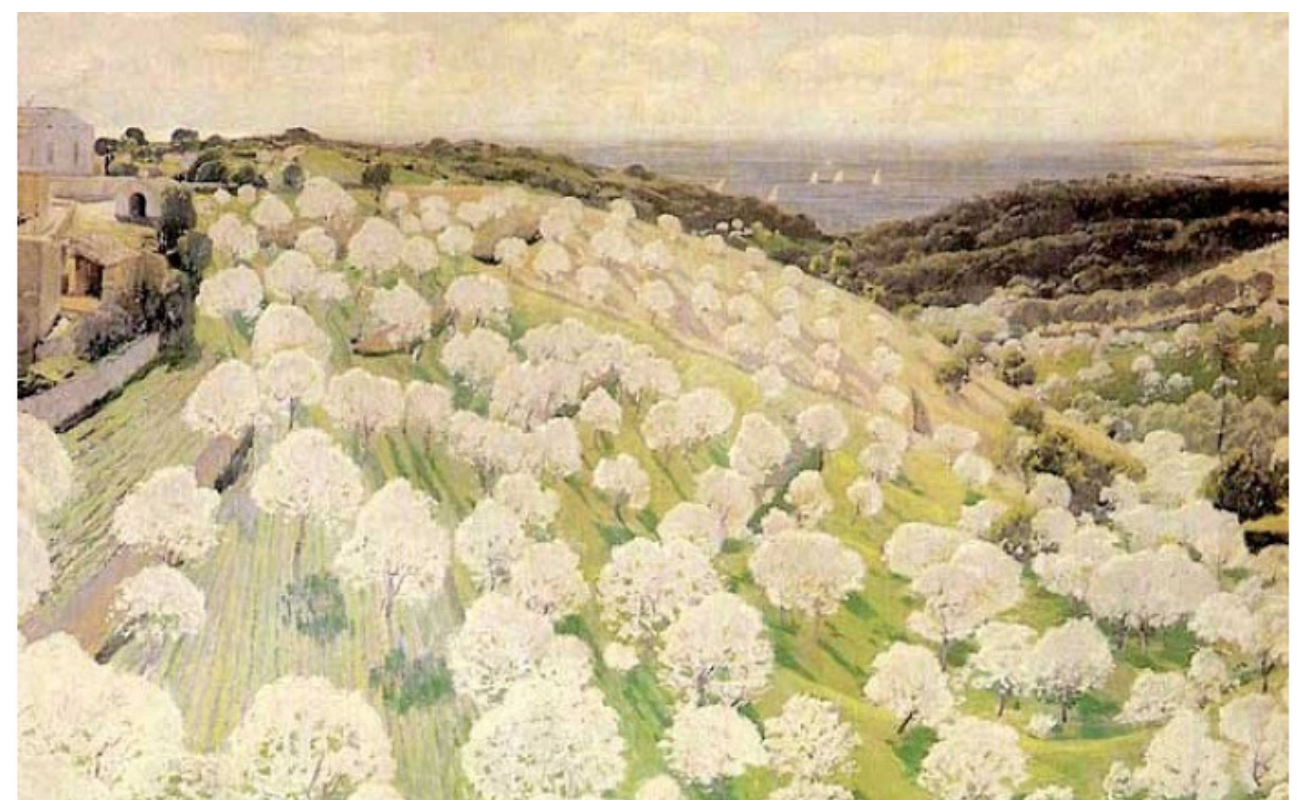

Figura 3. Almendros en flor en Mallorca. Santiago Rusiñol. Óleo sobre lienzo $(118 \times 137,3 \mathrm{~cm})$. Museo de Bellas Artes de La Habana, Cuba.

\section{Floración y turismo en Mallorca}

El viaje turístico a Mallorca con destino a los campos en flor viene en buena parte motivado por las peculiaridades geográficas, culturales y climáticas de la región mediterránea. En este sentido hay que tener en cuenta que el clima mediterráneo ha generado el 10\% (unas 25.000 especies) de la diversidad florística mundial en un 1,6\% del territorio del planeta, que además ha estado secularmente sometido a una de las mayores acciones de transformación antrópica del mundo, lo que ha dado lugar a una notable diversidad agrobiológica y en definitiva paisajística. También es bien conocido que en Mallorca se produce una fuerte concentración de la oferta y la demanda turística durante la estación estival, lo que conlleva el dominio de la modalidad del denominado turismo de 'sol y playa'. Los datos mensuales de establecimientos turísticos abiertos lo demuestran: en julio de 2019 estaba abierto el 97,8\% de la planta hotelera, mientras que en enero sólo lo estaba el 5,9\% y en febrero el 13,4\% (Agencia de Estrategia Turística de las Islas Baleares, 2020).

Por otra parte, mientras la costa ha sido y es una consagrada proveedora de servicios turísticos, las áreas interiores van a la zaga. Ciertamente, el espacio rural de Mallorca no ha quedado al margen de cambios en el paisaje provocados por la transfor- 
mación del mundo agrícola (sobre todo a partir de su mecanización y motorización), aunque en él siguen vigentes las actividades típicamente asociadas al sector primario -agricultura y ganadería-. Esos cambios iban a tener un efecto significativo en el turismo posterior de dos maneras:

Construyeron un campo más doméstico y mejor mantenido, que los nuevos visitantes encontraron accesible y atractivo -una distracción del mar, el sol y la arena-, y con el almendro, con su mar de flores rosadas, construyeron un elemento paisajístico que cada febrero pasa a formar parte del "precioso cuadro" amado por una generación de primeros visitantes bastante más románticos (Buswell, 2011, pp. 33-34).

En relación con esta domesticación del medio rural y su mantenimiento efectivo, hay que decir que el paisaje agrario de Mallorca, predominante en la mitad de la isla, es una realización humana que sobrevive gracias a un número realmente insignificante de personas. Para explicar esto puede verse que en junio de 2020 eran 4.221 los trabajadores afiliados a la Seguridad Social dedicados a la agricultura, la ganadería, la caza y servicios relacionados, según fuentes del Institut d'Estadística de les Illes Balears (IBESTAT). Si para el conjunto de sectores económicos el número de afiliados era de 393.128 -mayoritariamente en el sector de la hostelería (19,3\%), el comercio (16\%) y la construcción (10,6\%)-, puede inferirse así que apenas el 1,07\% de la población activa de Mallorca es responsable directo de la conservación del 48\% del paisaje mallorquín -el dedicado a cultivos y pastos, y que forma una parte destacada de la postal turística con la que se publicita la isla-.

En lo que se refiere a la acompasada turistización del interior rural mallorquín, cabe recordar que una de las medidas de la Politica de desarrollo rural de la Unión Europea para 2007-2013 era precisamente la "diversificación de la economía rural a través de ayudas para el desarrollo de actividades no agrícolas, ayuda a la creación y el desarrollo de pequeñas empresas y el fomento de actividades turísticas" (Sáenz y Cejudo, 2008). Por su parte, en la Estrategia de turismo sostenible para las Islas Baleares 20172020 se señala la necesidad de poner en valor los "productos y experiencias de turismo en las zonas de interior". En Mallorca así ha sido, y ya hemos señalado que en el desarrollo de la actividad turística en estas zonas ha jugado un papel determinante, directamente o sutilmente, la creación de una imagen de marca sustentada en la floración de los almendros. Ésta ha suscitado la creación de ciertos estereotipos paisajísticos y arquetípicos tales como "la nieve mallorquina" o "la Mallorca blanca". Se trata de una imagen utilizada recursivamente en las campañas de comunicación informativa y promocional del interior rural como destino turístico.

Hay que decir que el reconocimiento carismático de la floración del almendro no es exclusivo de Mallorca. En España tienen este reconocimiento áreas como Guaro (Málaga), el Valle del Pop (Alicante), la Quinta de los Molinos (Madrid), Villalpardo (Cuenca), Campo de Cagitán (Murcia), Santiago del Teide (Tenerife), Loarre (Huesca), Garrovi- 
llas de Alconétar (Cáceres) o Filabres-Alhamilla (Almería). Como en estos casos, el ocio y el turismo de floración en Mallorca opera claramente como un activo desestacionalizador -pues se desarrolla básicamente en los últimos meses de invierno-, al tiempo que redistribuye la actividad turística hacia áreas rurales del interior. El turismo en estas áreas cuenta con el complemento de los establecimientos turísticos. En 2019, la Agència d'Estratègia Turística de les Illes Balears (2020) contabilizaba en Mallorca 284 establecimientos de la modalidad de Agroturismo ${ }^{1}$, y 37 de la modalidad de Hotel Rural ${ }^{2}$.

En buena parte del espacio rural mallorquín la floración de los millones de almendros inventariados transforma el paisaje invernal en un tapiz floral de color blanco y rosáceo. La estampa ha sido y es aprovechada turísticamente en forma de itinerarios invernales que pueden recorrerse tanto en un vehículo a motor como en bicicleta o a pie. Estos itinerarios se realizan preferentemente a lo largo de la ruta central que une el municipio de Palma con la localidad de Sencelles, pero también con las localidades montañosas o de ladera de Bunyola y Esporles. En el levante y sur insular también son objeto preferente de visitas los municipios de Felanitx, Sant Llorenç, Santanyí o Llucmajor (Figura 2).

Se trata de visitas itinerantes que se comercializan desde los años 90 a través de operadores turísticos locales, pero también, y sobre todo, a través de touroperadores mayoristas como TUI o el extinto Thomas Cook, siendo su mercado preferente el alemán, es decir un tipo de turista con gran poder adquisitivo que valora el viaje a Mallorca fuera de la época veraniega. Según datos periodísticos, la llamada "operación flor de almendro" desplaza hasta Mallorca unos 50.000 turistas germanos entre enero y febrero, y ciertos establecimientos hoteleros de lujo ofrecen vuelos en helicóptero para contemplar desde el aire los campos en flor. Al ser una actividad típicamente invernal, el turista asume ciertas condiciones de frío, aunque los inviernos mallorquines son relativamente suaves. De hecho, una parte del atractivo turístico de la floración estacional - es decir su potencial para ser transformado en un producto turístico con capacidad de influir en el proceso de decisión del turista provocando su visita- proviene de las condiciones atmosféricas en las que tiene lugar la visita. En Mallorca se cumplen las exigencias fundamentales de confort, disfrute y seguridad por las que pasa el ideal climático-meteorológico del turista medio (Gómez-Martín, López Palomeque y MartínVide, 2002; Coll y Seguí, 2014).

1. Agroturismo se define en Baleares como aquel establecimiento que presta el servicio de alojamiento turístico ubicado en edificaciones construidas antes del 1 de enero de 1960, situadas en suelo rústico y en una finca o fincas que tengan una superficie mínima de $21.000 \mathrm{~m}^{2}$ y que constituyan una explotación agraria, ganadera o forestal.

2. Hotel rural se define en Baleares como aquel establecimiento que presta el servicio de alojamiento turístico y está ubicado en edificaciones construidas antes del 1 de enero de 1940, situadas en suelo rústico y que disponen de una superficie mínima de terreno de $49.000 \mathrm{~m}^{2}$, que ha de quedar vinculada a la actividad. 
Finalmente, el turismo florístico es revestido en Mallorca como un producto temático que incluye no sólo la contemplación de los campos en flor mediante el paseo a pie, sino también el senderismo, el cicloturismo o la gastronomía vernácula. De hecho, la almendra se traduce gastronómicamente en un conjunto amplio de productos culinarios: turrón, helado, pasteles, leche, salsas, o bien la almendra sola desnuda, que puede ser cruda, frita o asada, además de dulce o salada. También se obtiene aceite para usos farmacéuticos y cosméticos. Además de esto, la almendra tiene diferentes presentaciones comerciales (Socias i Company et al., 2013): en cáscara, en piel, tostada, repelada, harina de almendra, granillo de almendra, bastones de almendra o láminas de almendra. En relación con este aspecto, el ager mallorquín es un reflejo de los alimentos que consumen los habitantes del lugar, ya que la tradición culinaria encuentra su primer sustento en los productos agrícolas cultivados en el espacio agrario histórico. No obstante, esa misma tradición se está viendo alterada por la internacionalización de los hábitos alimenticios y por las normas que rigen la comercialización de los productos agrícolas. Por eso mismo, que en Mallorca y en mundo se conserve una gastronomía relacionada con el almendro puede resultar la clave para que también se mantenga activa la estampa de los campos de almendros en flor.

\section{La floración de frutales de clima templado: imagen de marca paisajística y turística del Baix Segre}

De acuerdo con las cifras oficiales del Censo Agrario de 2009 (el último disponible), los frutales de clima templado (básicamente manzano, peral, albaricoquero, cerezo, melocotonero, nectarino, ciruelo y guindo) ocupaban en Cataluña una superficie cultivada de $46.176 \mathrm{Ha}$, el 50,8\% de la cual localizada en la comarca del Segrià y el 24,6\% en la subcomarca del Baix Segre. Estas cifras evidencian la dedicación monotemática a estos frutales en estas dos últimas regiones, dedicación que se sustenta en el regadío, amparado por los grandes canales y acequias con base en el río Segre (Casals, 2018). En lo que se refiere, en concreto, al Baix Segre, las cifras más actuales de cultivos, correspondientes al año 2019, son un reflejo fiel de la huella territorial de los frutales y de su extraordinaria huella paisajística cuando florecen: los frutales de fruta fresca totalizan aquí $12.424 \mathrm{Ha}$ (el 30,7\% del territorio del Baix Segre). Si se suman los almendros, se alcanzan las $14.091 \mathrm{Ha}$. Destacan, sobre todo, los cultivos de melocotonero y de nectarino, y en menor medida el peral, el albaricoquero y el cerezo, al que suele unirse el guindo (Tabla 1). Si se atiende a los datos cartográficos de ocupación del suelo del proyecto Corine Land Cover para el año 2018 (Figura 4), la categoría 'Frutales' totaliza en la comarca del Baix Segre 19.438,0 Ha, siendo los municipios mejor representados Alcarràs (4.198 Ha), Aitona (4.168,6 Ha) y Seròs $(3.545,9$ Ha). 
Tabla 1. Superficie ( $\mathrm{Ha}$ ) de los cultivos de frutales de clima templado en el Baix Segre (año 2019)

\begin{tabular}{|l|c|c|c|c|c|c|c|c|}
\hline Municipio & Manzano & Peral & Albaricoquero & $\begin{array}{c}\text { Cerezo y } \\
\text { Guindo }\end{array}$ & Melocotonero & Ciruelo & Nectarino & Almendro \\
\hline Aitona & 4 & 207 & 106 & 43 & 1.365 & 6 & 1.036 & 227 \\
\hline Alcarràs & 83 & 236 & 84 & 59 & 1.112 & 9 & 1.297 & 158 \\
\hline Granja d'Escarp, la & 7 & 50 & 165 & 89 & 341 & 2 & 83 & 94 \\
\hline Massalcoreig & 4 & 153 & 91 & 22 & 409 & 4 & 177 & 6 \\
\hline Seròs & 18 & 161 & 319 & 187 & 658 & 13 & 296 & 1.009 \\
\hline Soses & 21 & 130 & 27 & 21 & 579 & 1 & 570 & 84 \\
\hline Torres de Segre & 145 & 277 & 43 & 12 & 967 & 0 & $\mathbf{7 3 5}$ & 89 \\
\hline TOTAL & $\mathbf{2 8 2}$ & $\mathbf{1 . 2 1 4}$ & $\mathbf{8 3 5}$ & $\mathbf{4 3 3}$ & $\mathbf{5 . 4 3 1}$ & $\mathbf{3 5}$ & $\mathbf{4 . 1 9 4}$ & $\mathbf{1 . 6 6 7}$ \\
\hline
\end{tabular}

Fuente: Elaboración propia a partir de datos del Departament d'Agricultura, Ramaderia i Pesca, Generalitat de Catalunya.

Baix Segre

Distribución municipal de frutales

(Corine Land Cover, 2018)

Frutales

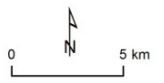

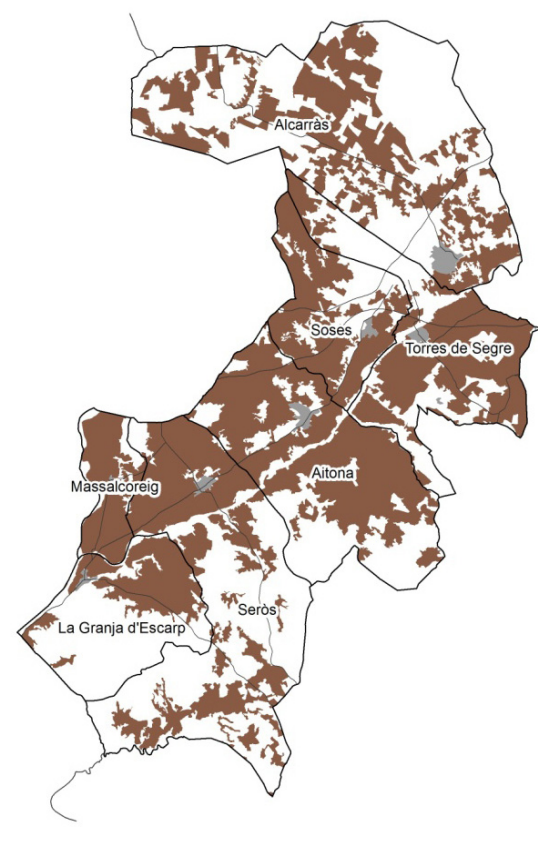

Figura 4. Baix Segre (Cataluña): Distribución municipal de los frutales (año 2018). Fuente: Elaboración propia a partir de los datos de ocupación del suelo del proyecto Corine Land Cover, 2018. 
Estas cifras también son un reflejo de la transformación agraria de la ribera del río Segre hacia la primera mitad del pasado siglo, cuando las tierras forrajeras para vaquería fueron paulatinamente substituidas por plantaciones masivas de fruta de verano para su comercialización y exportación a gran escala (García Manrique, 1971). Con esto, el agricultor leridano devino fruticultor, y la fruticultura devino la base de la riqueza comarcal. Antes de esto, los cultivos tradicionales del melocotonero, el ciruelo o el peral se reducían a los lindes del campo de cultivo (la denominación técnica de "árboles diseminados" proviene de esta ubicación) y a ciertas variedades locales, que servían sólo de complemento a la actividad de producción lechera.

La subcomarca del Baix Segre está situada al sudoeste del Segrià, y abarca los municipios de Aitona, Alcarràs, la Granja d'Escarp, Massalcoreig, Seròs, Soses y Torres de Segre. La región está recorrida por el curso fluvial del río Segre, lo que ha favorecido la formación de llanuras aluviales que han sido aprovechadas para la agricultura. Sin embargo, como señala Casals (2018), aunque el río Segre da nombre a la región, sólo Torres de Segre está directamente bañada por el río. Geomorfológicamente, se trata de una región de relieves ondulados y suaves que aumentan su altura a medida que se alejan del curso del río. Las frecuentes parcelas agrícolas forman un mosaico con formas y dimensiones diferentes, que se adaptan a las fluctuaciones del relieve (Nogué y Sala, 2010). El régimen de precipitaciones (alrededor de $400 \mathrm{~mm}$ anuales) no colabora, y de hecho se deriva del clima subárido continental característico de la comarca (Casals, 2018). Este clima se traduce aquí en áreas de vegetación subdesértica natural, similares a lo que se ha venido en llamar western americano, pero que contrastan con los frondosos campos frutícolas de regadío que, según la estación del año, cambian de coloración y dan como resultado unos paisajes diferenciados e igualmente muy contrastados.

Al tratarse de una zona microclimáticamente más cálida, en términos comparativos en el Baix Segre la fruta madura precozmente, unos días antes que en la zona de la denominada -y famosa- 'huerta de Lleida', al norte de nuestra subcomarca. En ella el movimiento frutícola se sustenta no sólo en un sistema de regadío de origen medieval basado en acequias, sino también en unos condicionantes naturales de suelo y de clima. En cuanto al suelo, en las terrazas del río el contenido de cal es menor, y en cuanto al clima, es el óptimo para la fruticultura de árboles de hoja caduca, pues en invierno se tiene el frío suficiente, y en verano el calor y las necesarias horas de sol. La consecuencia es un microclima con unas temperaturas 'de primavera' (de febrero a mayo) más elevadas que en la zona de la huerta de Lleida.

Los estadios fenológicos o de desarrollo de los árboles frutales indicados indican que florecen, sobre todo, en marzo. Es el caso del melocotonero (Prunus persica Batsch, además de sus variedades el Prunus persica var. Platycarpa-paraguayo-, el Prunus persica var. Nectarina-nectarina- y la platerina), que da lugar a una flor relativamente grande y de un característico color rosa (Figura 5), más intenso en el caso de la platerina. En cuanto al ciruelo (Prunus domestica), marzo también es el mes habitual de floración, justo después de que lo hagan los almendros. Su flor es blanca y pequeña, muy 
apretada, y recubre toda la rama. El albaricoquero (Prunus armeniaca B.) puede florecer precozmente en febrero, pero lo hace sobre todo en el mes siguiente. Su flor también es blanca, aunque con algún toque rosado. Por su parte, el peral (Pyrus communis) florece a primeros de abril y su flor es blanca y no muy grande. A diferencia de las del ciruelo, que parecen invadir toda la rama, las flores del peral aparecen en grupos formando pequeños bouquets naturales. Finalmente, el cerezo (Prunus cerasus) florece por lo común entre mediados de marzo y mediados de abril, dando lugar a un tipo de flor blanca, más grande y vistosa que la del peral (Saez, 2017).

El caso es que la economía del Baix Segre tiene una importante base agraria, que ha dado lugar al desarrollo de una destacada industria agroalimentaria, y son las explotaciones de fruta dulce, que se exporta internacionalmente, las que han garantizado el desarrollo económico al menos desde el último tercio del XX (Casals, 2015). Al mismo tiempo, como se verá, han servido de plataforma de lanzamiento de una actividad turística y de ocio cuyo reclamo es, precisamente, la floración estacional de los mencionados árboles.

\section{Floración y turismo en el Baix Segre}

La especialización agraria del Baix Segre en un tipo de cultivos dedicados a los árboles frutales de clima templado ha sido aprovechada en términos turísticos para sacar partido de los paisajes resultantes. Los campos de árboles en flor han sido objeto de valoración estética y esta valoración es hoy explotada con fines turísticos. Este reconocimiento no es exclusivo del Baix Segre, sino que también se reconoce, por ejemplo, en el valle del Jerte, en el extremo nororiental de Extremadura, donde es característico el paisaje de los estacionales cerezos en flor, que suman unos 1,5 millones de individuos en ese valle. También son conocidos los campos de melocotoneros de Cieza, en la Vega Alta del Segura (Murcia).

El desarrollo del Baix Segre como marca turística de carácter floral es relativamente reciente, y no arranca, como ocurre en Mallorca, del movimiento artístico y literario romántico 'descubridor' de los paisajes mediterráneos. En el caso catalán encuentra su origen hacia el año 2011, y culmina en el acuerdo de sus corporaciones municipales para promocionar turísticamente el territorio. Se trata, pues, de una marca turística más bien actual, que se ha servido eficazmente de las campañas publicitarias llevadas a cabo no sólo por el empresariado turístico en general, sino también por las instituciones públicas como la Diputación de Lleida y los ayuntamientos, con la colaboración del empresariado local dedicado a la industria agroalimentaria, así como de los agricultores locales. Con esto se pretende que la masa laboral de agricultores sea también la beneficiaria ulterior de la actividad turística desarrollada a propósito de sus campos de cultivo. De acuerdo con la clasificación en marcas turísticas que establece el organismo 
oficial Turisme de Catalunya, dependiente del Departament d'Innovació, Universitats i Empresa, el Baix Segre aparece incorporado como parte de la marca Terres de Lleida, denominación turística para el sector de poniente de la depresión central catalana, que tiene el río Segre como eje principal. Con datos del Institut d'Estadística de Catalunya (IDESCAT), esta marca había recibido en 2019 a 22.100 viajeros, de un total de 503.800 para ese año, lo que representa el 4,4\%, muy por detrás de la marca Pirineus $(33,9 \%)$ y de la marca Costa Brava (27,5\%).

La estampa que en la publicidad turística se presenta del Baix Segre es la de un paisaje singular y claramente diferenciado, como el que resulta de los cultivos de árboles en flor y sus cambios cromáticos estacionales. Esta singularización se refleja, por ejemplo, en los eslóganes con los que se publicita el turismo florístico en el municipio de Aitona -vehiculado a través de un proyecto propio denominado Fruiturisme, con el apoyo del Fondo Europeo de Desarrollo Regional (FEDER)-, eslóganes que tienen una clara invocación paisajística centrada en la coloración ambiental: "Aitona en flor", "Aitona en verd" (Aitona en verde) o "Un esclat de color" (Una explosión de color). Salvando las distancias, la floración de los cerezos en el Baix Segre adopta las características del hanami japonés, la tradición japonesa de observar la belleza de las flores del cerezo, para lo cual la población se desplaza a parques y jardines para contemplarlas y admirarlas. De manera parecida, bajo la mencionada iniciativa de Fruiturisme se propone un conjunto de Rutas del Árbol Frutal, algunas de ellas innovadoras, como la de los vuelos contemplativos en globo aerostático.

Según datos oficiales que presenta el mencionado sello Fruiturisme, en 2016 la campaña atrajo en el municipio de Aitona a 1.500 visitantes, 5.500 en 2017, 18.000 en 2018 y 20.000 en 2020, lo que significa una prueba del éxito de esta marca en particular. Las claves de este éxito residen en aspectos como los que a continuación se describen, relatados por el profesional Josep M. Capella Oliva. En primer lugar, el logro de encontrar un producto económico que en sí mismo ofrece las ventajas competitivas de ser único, atractivo, accesible, rentable, difícil de copiar y fácil de comunicar. En segundo lugar, la provincia de Lleida constituye un destino turístico tradicionalmente sustentado en el senderismo de montaña, los deportes de nieve o el patrimonio histórico-arqueológico, al que ahora se ha sumado la atracción por un nuevo producto como el de la floración, y que hasta hace poco había pasado desapercibida como posible recurso turístico. Se trata, además, de un recurso que permite invocar la autenticidad del lugar y el respeto por los ritmos naturales -es decir, los ritmos de la floración estacional-. En tercer lugar, la implicación de ciertos agentes turísticos, instituciones públicas y entidades privadas, además del campesinado local, ha colaborado para que el Baix Segre sea valorado inéditamente como destino en el mercado turístico. Con esto se ponen en práctica lo que Ivars (2000, pp.79-80) considera los fundamentos de los paradigmas de desarrollo rural en base al turismo, tales como la movilización de los recursos locales endógenos, la concertación entre administraciones y agentes implicados, la participación público-privada, la coordinación y cooperación entre administraciones afectadas, el mantenimiento de la población en los espacios rurales o la población local como máximo beneficiario. 
Por lo demás, el turismo de floración ofrece a los residentes implicados en la campaña oportunidades de negocio comercial operados localmente, al promover el uso y la venta de productos alimenticios locales, lo que ayuda a estabilizar la base económica del lugar. La calidad del paisaje florístico del Baix Segre no sólo se presenta como un indiscutible elemento de identidad, sino que constituye un factor clave de competitividad del territorio, ligada aquí a su riqueza agraria. Juega a favor de dicha competitividad una planificación del recurso a corto y largo plazo, conducente a asegurar su gestión eficiente, así como la puesta en funcionamiento de cursos de formación orientados a formar a los agentes locales para que conozcan la botánica de los árboles y las prácticas agrícolas, además de la geografía y la historia del lugar. Además de esto, se ha conseguido ampliar la oferta de la floración estacional con otro tipo de servicios complementarios con los que completar las visitas, tales como la comercialización directa de productos alimenticios procedentes de los terrenos de cultivo.

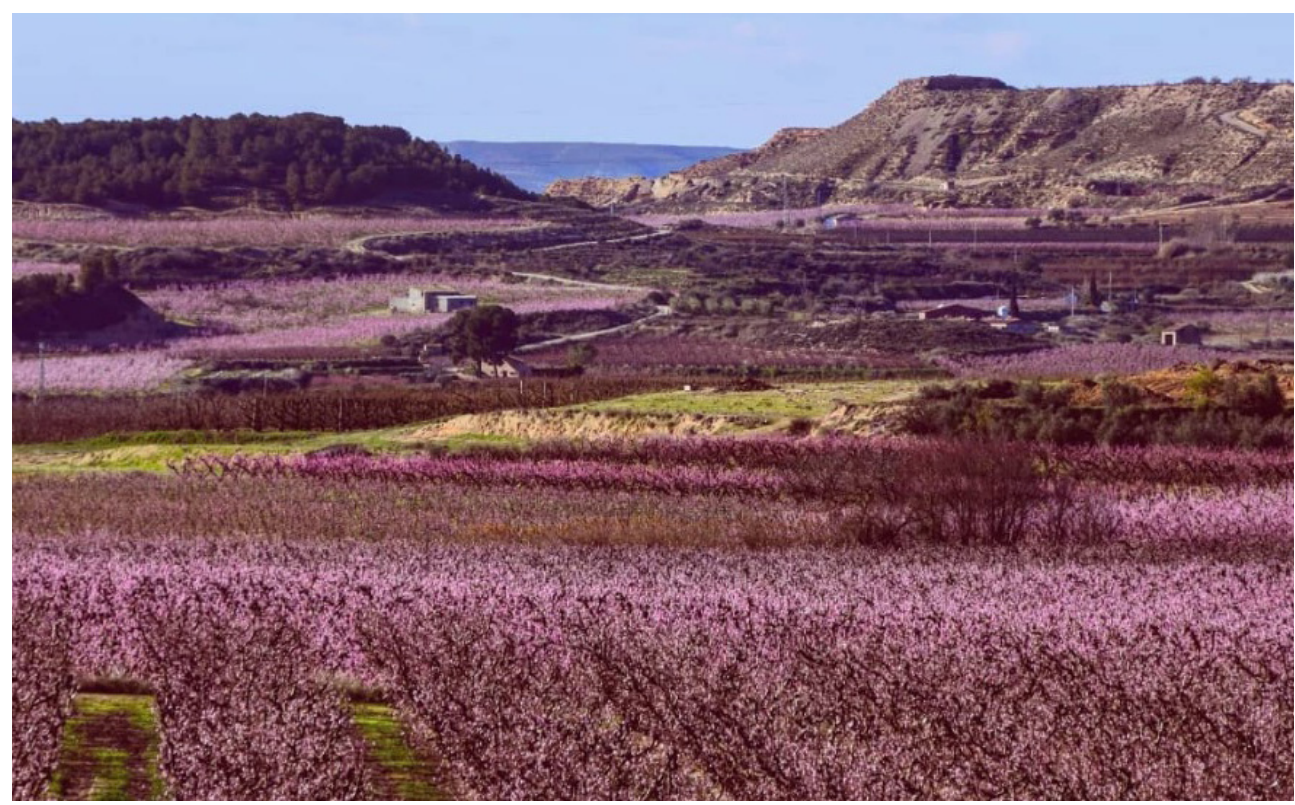

Figura 5. Campos de melocotoneros en el municipio de Soses.

Fuente: Archivo Municipal de Soses.

Según Casals (2015), en el Baix Segre el paisaje de los campos de frutales en flor puede contemplarse y admirarse de manera óptima desde la colina de Carrassumada (200 $\mathrm{m}$ de altitud), a 2,5 km de Torres de Segre. Otros miradores privilegiados son los de Sant Joan de Carratalà (Aitona), Montmeneu (Seròs), la pista de Costa Genebral (la Granja d'Escarp) o l'oppidum ibérico de Gebós (Soses). Miradores territoriales como estos no 
sólo permiten la apropiación eficaz del paisaje, sino que juegan a favor de la creación de relaciones afectivas y emotivas con el lugar, tanto por parte de la población local como de los visitantes externos. Además de esto, tienen la función pedagógica de la comprensión e interpretación del territorio propio, con lo que esto tiene de conformación de identidades y de sentimientos de pertenencia (Govers, 2009), pues el paisaje es expresión material, espiritual y simbólica del país. En relación con esto, el referente ideológico al cual se apela en la construcción de la imagen de marca territorial y turística de espacios agrarios como los del Baix Segre, no es otro que el movimiento Cittaslow. En relación con él y con su aplicación en Cataluña, San Eugenio y Barniol (2012) han estudiado el caso de la marca Territoris serens, con la que se creó una imagen competitiva para la agrupación territorial catalana del Lluçanès. Por otra parte, ese tipo de afectos por el territorio y sus paisajes, analizados por Tuan en un ensayo famoso (Topofilia, 2007), hace que los actores se impliquen en un desarrollo turístico que conserve las esencias del lugar, su historia natural y agraria, y sus usos y costumbres tradicionales.

\section{Conclusiones}

El turismo de flora constituye hoy una opción consolidada dentro del conjunto de actividades turísticas y de ocio caracterizadas como "alternativas". En las áreas rurales de las regiones examinadas en el presente trabajo, la actividad agraria y sus consiguientes paisajes ha sido explotada profusamente por la industria turística, para lo cual se ha necesitado de la creación de una imagen de marca territorial y paisajística específica: la floración invernal del almendro en Mallorca y la floración primaveral de los frutales de clima templado en el Baix Segre (principalmente melocotonero, nectarino, peral, cerezo y albaricoquero). Así como, en Mallorca, de los almendros en flor han surgido carteles y postales turísticas, viajes de luna de miel, poemas, novelas, perfumes y fiestas locales, en el Baix Segre la especialización agraria y su riqueza frutícola ha sido aprovechada como eje vertebrador de su principal oferta de ocio y turismo, amparada además por las corporaciones locales. Se trata de un turismo aparentemente compatible con los valores ambientales y culturales de estas dos regiones. No en vano, el turismo de floración está fuertemente vinculado a la calidad ambiental y sociocultural de los entornos rurales, cuyos recursos florísticos ejercen un poder de atracción sobre una clase de turistas especialmente interesados en la experiencia sensorial y estética que proveen dichos recursos. Este interés ha llevado a la mercantilización con fines turísticos de los entornos rurales de las comarcas examinadas, con una apoyatura publicitaria consistente en la estereotipación de los paisajes que resultan de la floración de los árboles. Su consumo turístico se realiza siempre a tiempo parcial y en la estación invernal (Mallorca) o primaveral (Baix Segre). En los destinos como Mallorca, caracterizados por la monopolización del turismo de 'sol y playa', este tipo de turismo, aunque minoritario, colabora en la ampliación y diversificación de la oferta, así como tam- 
bién en su desestacionalización. En Mallorca, el modelo turístico es ya multiproducto (sol y playa, cicloturismo, senderismo, turismo de aventura, enoturismo, turismo florístico, turismo residencial, turismo de golf, turismo náutico); mientras que en el Baix Segre el modelo no está tan diversificado, y se reduce al senderismo y el cicloturismo, en asociación con el consumo turístico de los espacios de producción agraria.

Desde un punto de vista crítico, con la imagen de marca paisajística de los frutales en flor se pretende sugerir al turista la idea roussoniana de un mundo en el que naturaleza y actividad humana todavía se unen en un equilibrio perfecto, unión que con la ciudad parece que ha quedado suprimida. Es por esto por lo que los paisajes agrarios de Mallorca y el Baix Segre, junto con sus etno-paisajes, se utilizan como el decorado que suscita ideales éticos relacionados con la bondad, con la supuesta virtud del campesino, y con un figurado estilo de vida apartado de las corrupciones que conlleva la vida urbana. No en vano, las imágenes de marca del turismo de floración se alimentan de la herencia del naturalismo y el costumbrismo romántico decimonónico, que en Mallorca puso las bases iconográficas de la publicidad turística centrada en el paisaje. El territorio rural en las regiones examinadas se publicita en forma de imágenes que representan piezas bien presentadas de este territorio, como decorados cuidadosamente expuestos. En estas piezas se da un especial significado a los elementos integrantes de la trama rural, que son el espacio agrario, pero también los caminos que comunican los campos y pueblos, así como las edificaciones históricas propias del hábitat rural, muchas de las cuales patrimonizadas y cargadas de valor paisajistico.

\section{Bibliografía}

Agència d'Estratègia Turística de les Illes Balears (2020). El turisme a les Illes Balears. Anuari 2019. Conselleria de Model Econòmic, Turisme i Treball. Govern de les Illes Balears.

Alomar-Garau, G.; Grimalt-Gelabert, M.; Bauzà-Llinàs, J. (2020). Determinación cartográfica de los muros de piedra seca de la Sierra de Tramuntana mallorquina (Islas Baleares): Análisis exploratorio. Cuadernos Geográficos, 59 (3), pp. 142-157 DOI: http://dx.doi.org/10.30827/cuadgeo. v59i3.11424

Alzaga, A. (2005). El viaje a Mallorca en el siglo XIX: la configuración del mito romántico y de sus itinerarios artísticos. Espacio, Tiempo y Forma 18-19, pp. 163-193.

Archiduque Luis Salvador de Áustria ([1871] 1959). Las Baleares descritas por la palabra y el grabado. Mallorca agrícola (primera mitad). Palma de Mallorca: Imprenta Mossèn Alcover. Traducción del alemán por José Sureda Blanes.

Ballantyne, R., Packer, J. y Hughes, K. (2008). Environmental Awareness, Interests and Motives of Botanic Garden Visitors: Implications for Interactive Practice. Tourism Management, 29 (3), pp. 439-44. DOI: https://doi.org/10.1016/j.tourman.2007.05.006

Barke, M. (2004). Rural tourism in Spain. The International Journal of Tourism Research, 6, pp. 137-149 DOI: https://doi.org/10.1002/jtr.480 
Bes Hoghton, I. (2012). Le paysage sublime de l'île mediterranéenne dans la littérature de voyage du xixéme siècle: du locus amoenus au locus horribilis. Thélème. Revista Complutense de Estudios Franceses, 27, pp. 71-85 DOI: http://dx.doi.org/10.5209/rev_THEL.2012.v27.38924

Busby, G. y Rendle, S. (2000). The transition from tourism on farms to farm tourism. Tourism Management, 21 (8), pp. 635-642 DOI: https://doi.org/10.1016/S0261-5177(00)00011-X

Buswell, R.J. (2011). Mallorca and Tourism. History, Economy and Environment. Bristol, Buffalo, Toronto: Channel View Publications.

Casals, Q. (2015). El Baix Segre: una proposta de turisme de proximitat. Arts: revista del Cercle de Belles Arts de Lleida 40, pp. 49-53.

Casals, Q. (2018). El Segrià a estudi: Definició de l'espai i la seva gent. Shikar. Revista del Centre d'Estudis Comarcals del Segrià, 5, pp. 27-36.

Cebrián, F. (2013). La función del paisaje como recurso territorial turístico en zonas de interior. Observatorio Medioambiental, 16, pp. 37-54. DOI: https://doi.org/10.5209/rev_OBMD. 2013.v16.43199

Cela, C.J. (1979). Capitalismo y campesinado en la isla de Mallorca. Madrid: Siglo XXI.

Cohen, E. (2004). Contemporary Tourism: Diversity and Change. Amsterdam: Elsevier.

Cohen, E. y Fennell, D. (2019). Plants and tourism: Not seeing the forest [n]or the trees. Tourist Studies, 19 (4), pp. 585-606 DOI: https://doi.org/10.1177/1468797619864940

Coll, M.À. y Seguí, M. (2014). El papel del clima en la estacionalidad turística y la configuración de productos turísticos emergentes. El caso de Mallorca. Cuadernos de Turismo, 33, pp. 15-30.

Cosgrove, D.E. (1998). Social Formation and Symbolic Landscape. Madison: The University of Wisconsin Press.

d'Este, M. (1907). With a camera in Majorca. New York and London: G.P. Putnam's Sons, The Knickerbocker Press.

García, E. (1971). La evolución de los regadios leridanos hacia los cultivos de frutales. Papeles del Departamento de Geografía 3, pp. 9-133.

GOIB. Govern de les Illes Balears (2018). Estadístiques de l'Agricultura, la Ramaderia i la Pesca a les Illes Balears. Any 2018. Palma: Conselleria d'Agricultura, Pesca i Alimentació, Àrea Tècnica Agrària.

Gómez, Ma‥B., López, F. y Martín-Vide, J. (2002). Aptitud climática y turismo. Variaciones geográficas y cronológicas de la potencialidad climático-turística del verano en Cataluña. Ería 59, pp. 333-345.

Grasset, A. (1807). Voyage dans les iles Baléares et Pihiuses. Paris: De l'imprimierie de L. Haussmann.

Hermans, D. (1981). The encounter of agriculture and tourism a Catalan case. Annals of Tourism Research, 8 (3), pp. 462-479. DOI: https://doi.org/10.1016/0160-7383(81)90009-8

Ivars, J.A. (2000). Turismo y espacios rurales: conceptos, filosofías y realidades. Investigaciones Geográficas 23, pp. 59-88.

Laurens, J.B. (1840). Souvenirs d'un voyage d'art à l'île de Majorque. Paris: Imp. Arthus Bertrand \& Gihaut Frères. 
Lavedan, P. (1936). Palma de Majorque et les Iles Baleares. Paris: Librairie Renouard, H. Laurens Éditeur.

López, F. (1994). Actividad turística y espacio geográfico en el umbral del siglo XXI. Papers de Turisme 14-15, pp. 37-52.

Lozato-Giotart, J.P. (1990). Geografía del turismo: del espacio contemplado al espacio consumido. Barcelona: Masson.

Miossec, J.M. (1977). L'image touristique comme introduction à la géographie du tourisme. Annales de Géographie 473, pp. 55-70.

Nogué, J. y Sala, P. (2010). Catàleg de paisatge. Les Terres de Lleida. Barcelona: Departament de Política Territorial i Obres Públiques, Generalitat de Catalunya.

Padilla, A. y Such, M‥P. (2001). Biodiversidad florística y turismo en el litoral valenciano. En: Actas del XVII Congreso de Geógrafos Españoles (pp. 188-194) Oviedo: Asociación de Geógrafos Españoles.

Pickering, C. y Ballantyne, M. (2013). Orchids: An Example of Charismatic Megaflora Tourism?. En: Holden, A. y Fennell, D.A. (eds) The Routledge Handbook of Tourism and the Environment. (pp. 192-199). London: Routledge.

Picornell, C. (2008). Noms de varietats d'ametles a Balears. En: XXJornada d'Antroponimia i Toponímia (La Real, 2007) (pp. 27-33). Palma: Universitat de les Illes Balears.

Rusiñol, S. (1983). "Desde una Isla. En busca de un istmo". La Vanguardia, 2 de abril de 1893.

Ryan, J. (2011). Anthoethnography: Emerging Research into the Culture of Flora, Aesthetic Experience of Plants, and the Wildflower Tourism of the Future, New Scholar 1 (1), pp. 28-40.

Saez, A. (2017). "Un mar de flors". Diari Segre. Suplement dominical.

Salvà Tomàs, P.A. (1985). Turisme i canvi a l'espai de les Illes Balears. Treballs de la Societat Catalana de Geografia 2, pp. 17-32.

San Eugenio (de) Vela, J. y Barniol Casanova, M. (2012). Marcas territoriales y desarrollo local en la Cataluña interior. Estudio de caso: Territoris serens (el Lluçanès). Documents d'Anàlisi Geogräfica, 58 (3), pp. 417-439 DOI: https://doi.org/10.5565/rev/dag.2

Sáenz Lorite, M. y Cejudo García, E. (2008). La Política de Desarrollo Rural de la Unión Europea para 2007-2013. Investigaciones Geográficas 46, pp. 5-30.

Sánchez, J.E. (1985). Por una Geografía del Turismo Litoral. Una aproximación metodológica. Estudios Territoriales 17, pp. 103-122.

Saura, F. y Cañellas, J. (1981). Caracteres morfológicos y constitución química de variedades de almendra en Mallorca. Maina 3, pp. 14-19.

Seguí, M. (1995). Les nouvelles Baléares: la rénovation d’un espace touristique mythique. Paris: L'Harmattan, Collection Tourismes et Sociétés, 232 p.

Smith, V.L. (ed.) (1989). Hosts and guests: The Anthropology of Tourism. Philadelphia: University of Pennsylvania Press.

Sharpley, R. y Jepson, D. (2011). Rural tourism: A spiritual experience? Annals of Tourism Research 8 (1), pp. 52-71. 
Socias i Company, R.; Repollés, D.; Kodad, E.; Fernández i Martí, A.; Alonso, J.M. (2013). La valoración de la calidad de las nuevas variedades de almendro por una cooperación multisectorial. Revista de Fruticultura 29, septiembre-octubre de 2013.

Tao, G.H. (2011). Empirical Study on Management of Flowers Tourism. Journal of Landscape Research 3 (4), pp. 68-71.

Tuan, Y-F. (1979). "Thought and landscape: The eye and the mind's eye". En: Meinig, D.W. (ed) The Interpretation of Ordinary Landscapes (pp. 89-102). New York: Oxford University Press.

Tuan, Y-F. (2007). Topofilia. Barcelona: Melusina.

Turpie, J. y Joubert, A. (2004). The value of flower tourism on the Bokkeveld Plateau. A botanical hotspot. Development Southern Africa, 21 (4), pp. 645-662. DOI: https://doi.org/10.1080/ 0376835042000288833

Urech Cifre, C. (1869). Estudio sobre la riqueza territorial de las islas Baleares. Palma: Imprenta de F. Guasp.

Vives, A. (2005). Història del Foment del Turisme de Mallorca (1905-2005). Palma: Foment del Turisme de Mallorca.

Xie, Y.; Wang, X.; Meng, M.; Xiao, Y. (2005). Study on the Development of the Flower-Themed Tourism in Lin'an, Zhejiang. Journal of Zhejiang Forestry Science and Technology 252, pp. 65-68. 